\title{
Atmospheric Circulation Characteristics Favoring Dust Outbreaks over the Solar Village, Central Saudi Arabia*
}

\author{
E. E. Houssos \\ Laboratory of Meteorology, Department of Physics, University of Ioannina, Ioannina, Greece \\ T. CHRONIS \\ Earth System Science Center, University of Alabama in Huntsville, Huntsville, Alabama
}

A. FOTIADI

Department of Environmental and Natural Resources Management, University of Patras, Agrinio, Greece

F. HOSSAIN

Department of Civil and Environmental Engineering, University of Washington, Seattle, Washington

(Manuscript received 18 June 2014, in final form 23 February 2015)

\begin{abstract}
This study examines the atmospheric circulation characteristics of dust outbreaks (DOs) over the central Arabian Peninsula. Based on a 12-yr (1999-2011) Aerosol Robotic Network (AERONET) database over the Solar Village in Saudi Arabia and criteria pertinent to the aerosol optical depth at $500 \mathrm{~nm}$ and the Ångström exponent, 177 DOs have been identified. Factor and cluster analysis are further applied on the 1000- and 700-hPa geopotential height daily patterns of the days preceding the onset of the DOs and the days of the DOs' initiation, revealing four main types (clusters) of the atmospheric circulation evolution leading to DOs. During the winter season, the anticyclonic circulation intensifies over the Middle East causing the strengthening of the pressure gradient over the Arabian Peninsula, inducing northerly winds over the study region, thereby favoring dust entrainment in the atmosphere (cluster 1,16 DOs, 9\%). The passage of midlatitude cyclones over the northern or central Arabian Peninsula is frequently accompanied by postfrontal northerly winds also promoting the presence of DOs in the region (cluster 2, 41 DOs, 23\%). The DOs during spring are likely favored by the enhancement of convective activity, as the thermal low over the Arabian Peninsula further influences the dynamics of the upper troposphere (cluster 3, 73 DOs, 41\%). During summer the pressure gradient over the study region is greatly enhanced due to the extension of the subtropical Azores anticyclone over the Mediterranean. The latter is the main driver triggering the DOs in this cluster category (cluster 4, 46 DOs, 27\%).
\end{abstract}

\section{Introduction}

The understanding and predictability of dust storms have broad ramifications. Dust events are typically a nuisance to outdoor activities, but severe dust storms

\footnotetext{
* Supplemental information related to this paper is available at the Journals Online website: http://dx.doi.org/10.1175/MWR-D-14-00198.s1.

Corresponding author address: Themis Chronis, Earth System Science Center, University of Alabama in Huntsville, 320 Sparkman Dr., Huntsville, AL 35805.

E-mail: themis.chronis@nsstc.uah.edu
}

can be a serious hazard mainly to ground and air transportation and even to human health, because of increased particulate matter in air. Dust storms are also known to have an impact on the global energy and water cycle (Huang et al. 2010), as well as radiative effects (Ramanathan et al. 2001; Christopher and Zhang 2002), and they also play an important role in biogeochemical processes through increased deposition on land surfaces and contributing to soil development (Muhs et al. 2007). Dust storms contribute to the global transport of particulate matter across continental scales through synoptic processes, which sometimes even impact extreme events such as hurricanes (Lau and Kim 2007). Thus, improved 
understanding of these phenomena can potentially lead to better forecasting adaptation and planning.

The deserts of the Arabian Peninsula are among the most important and persistent dust sources worldwide (Middleton 1986; Prospero et al. 2002; Washington et al. 2003; Zender et al. 2003; Barkan et al. 2004; Tanaka and Chiba 2006; Ginoux et al. 2010, 2012). In particular, the Arabian Peninsula is a source of intense dust storms with an important contribution to the long-range transport of mineral aerosols over the Indian Ocean (Rajeev et al. 2000; Krishnamurti et al. 1998) and adjacent regions (e.g., the Arabian Sea and Iran) (Pease et al. 1998; Tindale and Pease 1999; Tanaka and Chiba 2006; Shao et al. 2011; Zhu et al. 2007).

Over the past few years numerous research efforts focused on the dust storm status in the Arabian Peninsula. Middleton (1986) carried out a climatological study of dust storm distribution over the Middle East documenting that central Saudi Arabia exhibited a moderate level of dust storm activity whereas the Tigris-Euphrates plains exhibited a relatively stronger one. Based on ground visibility data obtained from the National Climatic Data Center (NCDC), Kutiel and Furman (2003) studied the spatial and temporal characteristics of dust storms over the Middle East for the period 1973-93. The maximum dust storm activity (visibility $<11 \mathrm{~km}$ for more than $30 \%$ of the time during summer) was observed over the region encompassing Iran, Iraq, Syria, and countries neighboring the Persian Gulf and the southern Arabian Peninsula. According to Kutiel and Furman (2003), dust storms can be observed throughout the year, but the respective maximum frequency exhibits a clear seasonality that varies from the northwest occurring in winter and spring (visibility $<11 \mathrm{~km}$ for more than $5 \%$ of the time during winter and spring and around $1 \%$ during summer) to the south-southeast where they are most active and intense in summer (visibility $<11 \mathrm{~km}$ for more than $30 \%$ of the time during summer and around 5\% during winter). The same spatial and temporal patterns of dust storms are also documented by Rezazadeh et al. (2013) using visibility records for the period 1998-2003. Utilizing the Total Ozone Mapping Spectrometer (TOMS)-derived aerosol index (AI), for a 14.5-yr period (1978-93), the maximum of dust storm activity is identified over eastern and central Saudi Arabia (Ad Dahna Desert) as well as the Saudi-Oman border (Rub al Khali or Empty Quarter Desert) during the summer months (Washington et al. 2003). Prospero et al. (2002), also using TOMS measurements for the period 1980-92, confirmed that over the Arabian Peninsula dust storms develop throughout the year, following a distinct annual cycle with low activity during winter, strengthening between March and April, reaching a maximum during June and July. The same authors identified the areas of the eastern coast of the Persian Gulf, Oman, and southern Iraq as regions of intense dust storm activity. The study of a 1-yr period of aerosol optical properties from the Aerosol Robotic Network (AERONET) over Bahrain, Smirnov et al. (2002) determined that the highest dust concentration occurred during late spring and summer months. Similarly, a 10-yr climatological study of aerosol properties from the AERONET station in Solar Village in Saudi Arabia indicated the predominance of dusty conditions of a similar seasonal character (Kim et al. 2011).

While dust emission and resuspension is controlled by microscale processes, intense dust storms (i.e., in terms of total airborne mass, spatial extent, and duration) require strong and/or persistent wind conditions driven by meso- to synoptic-scale mechanisms. Frequently, dust storms in the Middle East and Arabian Peninsula are related to the postfrontal regime of midlatitude low pressure systems propagating eastward, also known as the winter Shamal wind (Rao et al. 2001; de Villiers and van Heerden 2007). Prefrontal winds (named "Kaus" in Saudi Arabia) can also trigger strong dust outbreaks (Alharbi 2008; Alharbi et al. 2013; Abdi Vishkaee et al. 2012; Hamidi et al. 2013). Conversely, the summer dust storms are related to the persistent strong surface flow, known as the summer Shamal wind, driven by the pressure gradient between the subtropical high pressure system and the Indian monsoon thermal low (Middleton 1986; Prospero et al. 2002; Rao et al. 2003; Washington et al. 2003; Abdi Vishkaee et al. 2011; Hamidi et al. 2013). Finally, on a smaller scale, numerous dust storms originate from convective storms that induce strong downdrafts, known as Haboobs (Miller et al. 2008; Alharbi 2008).

Several studies have focused on the relationship between dust storms and the prevailing synoptic conditions over the broader area encompassing the Middle East. Maghrabi et al. (2011) and Alharbi et al. (2013) examined an intense dust storm that occurred in March 2009 over central-eastern Saudi Arabia and the Persian Gulf. Using satellite images and synoptic charts they found out the relation of the dust storm occurrence with the coincidence of a cold front passage and the propagation of an upper-level jet streak. Also, Abdi Vishkaee et al. (2011, 2012), investigating two dust storm cases in August 2007 and February 2010, examined the dynamical processes leading to dust emission and associated the dust transport over Iraq and northwestern Iran with the strong summer and winter Shamal, respectively. Kalenderski et al. (2013) used a regional meteorological 


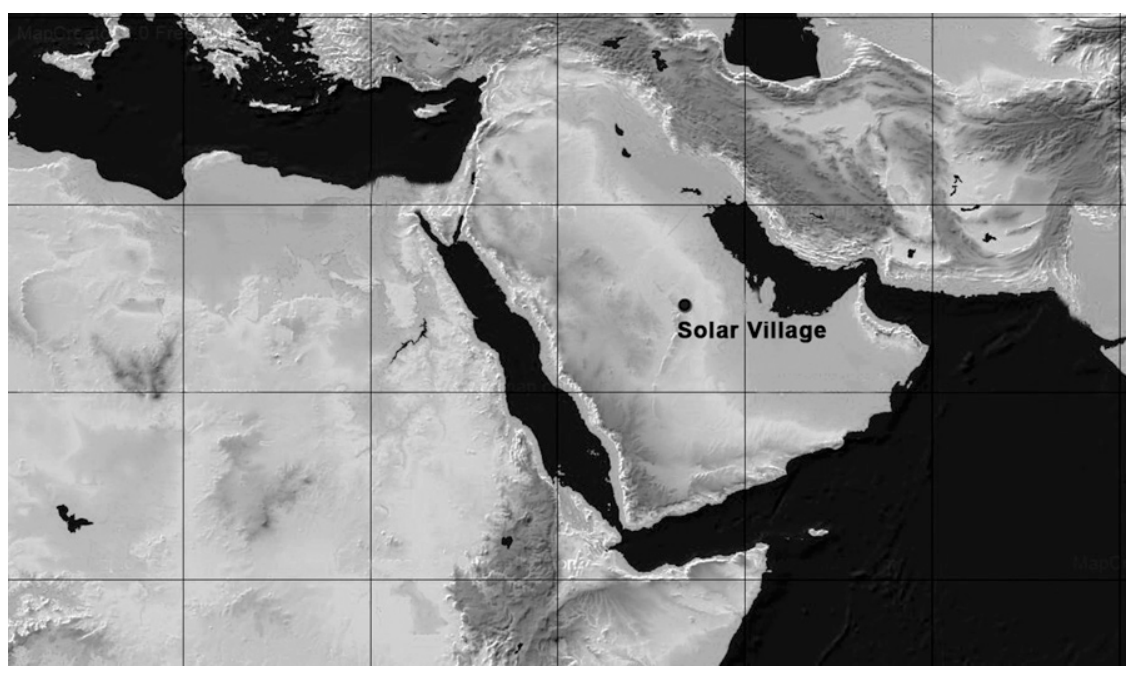

FIG. 1. The study area where the location of Solar Village (central Saudi Arabia) is denoted.

model coupled with an aerosol-chemistry component to simulate a typical winter dust event over the Arabian Peninsula and the Red Sea. They concluded that dust in the atmosphere can cause a significant reduction of downward solar radiation with a cooling effect reaching $100 \mathrm{~W} \mathrm{~m}^{-2}$. Ghasem et al. (2012) analyzed the frequency of occurrence of dust events in southwestern Iran over a 30-yr period from 1979 to 2008, but for their synoptic analysis they studied only one dust storm in September 2008. They revealed the role of atmospheric instability to the dust entrainment into the atmosphere and the influence of the pressure gradient intensification between the Caspian high pressure system and the thermal low in the southestern Arabian Peninsula on wind speed and dust transport over the Middle East. Based on MODIS satellite images, Hamidi et al. (2013) identified 60 dust storms over the broader area of the Middle East during the period 2003-11 and attempted a subjective classification of synoptic patterns of the 12 most severe. They grouped dust storms in two categories: the Shamal (summer) dust storms and the frontal ones while for each category, via a composite analysis, they determined the location of low and high pressure systems driving flow field over the study area. All the aforementioned scientific works depict the synoptic conditions that favored specific dust storms (case studies) are often exceptionally strong. Current literature does not thoroughly cover the synoptic atmospheric conditions that lead to dust storm outbreaks.

In the present study a significant number of dust outbreaks (177 over a 12-yr period from 1999 to 2011) that occurred over the Solar Village AERONET station are identified, utilizing aerosol optical properties such as the aerosol optical depth and the Ångström exponent.
While the use of combined values of aerosol optical depth and Ångström exponent as criteria for the definition of dust episodes is common practice (Kubilay et al. 2003; Gkikas et al. 2009), this is the first time that these are employed as proxies for the Arabian Peninsula dust storms, since previous works were based mainly on visibility data or MODIS images. The methodology comprising multivariate statistical methods of factor and cluster analysis, is subsequently used to objectively classify a large number of daily $1000-$ and $700-\mathrm{hPa}$ geopotential height patterns that correspond to the identified dust outbreaks days into discrete clusters. The analysis of the mean 1000- and 700-hPa geopotential height patterns of each cluster reveals the main characteristics of the atmospheric circulation related to high dust concentrations over the Solar Village in the central Arabian Peninsula. In section 2 the study region and the employed data are presented, in section 3 the methodology is described in detail. The atmospheric circulation types associated with dust outbreaks are discussed in section 4. Finally, the main conclusions of this study are outlined in section 5 .

\section{Study region and data}

\section{a. Study region}

Solar Village is located in the center of the Arabian Desert, $50 \mathrm{~km}$ northwest of Riyadh, in central Saudi Arabia (Fig. 1). It is surrounded by the An-Nafud Sand Sea in the north, the Rub Al Khali Desert in the south, one of the largest sand deserts in the world, and the Ad-Dahna Desert, a sand corridor $1287 \mathrm{~km}$ long in the east. Through the years several projects of exploitation of solar energy for electricity production, such as the Solar-Powered 
Hydrogen Utilization Project and the Photovoltaic Research Project, have been developed around the Solar Village. Since 1981, a Photovoltaic Power System (PVPS) of $350 \mathrm{~kW}$ [2155 megawatt hours (MWh)] has been operating in this region, supplying the three neighboring villages with $1-1.5 \mathrm{MWh} \mathrm{day}^{-1}$. The experience gained along with research results, have shown energy loss and a general efficiency decrease due to airborne dust (Alawaji 2001).

\section{b. Aerosol data}

To identify dust outbreaks (DOs), the level-2.0 aerosol optical depth (AOD) daily mean values at $500 \mathrm{~nm}$ $\left(\mathrm{AOD}_{500}\right)$ from the AERONET station of Solar Village in Saudi Arabia $\left(24.9^{\circ} \mathrm{N}, 46.4^{\circ} \mathrm{E}\right.$, altitude $\left.764 \mathrm{~m}\right)$, are used. The $\mathrm{AOD}_{500}$ values are derived from measurements made with a CIMEL (CE-318) spectral radiometer (Holben et al. 1998, 2001) expanding over a 12-yr period (22 February 1999-30 September 2011). Additionally, values of the Ångström exponent $\alpha$, computed from aerosol optical depth at 440 and $870 \mathrm{~nm}\left(\alpha_{440-870}\right)$, are employed.

\section{c. Atmospheric circulation data}

For the identification of the atmospheric circulation types associated with DOs in central Saudi Arabia, atmospheric gridded data are employed from the NCEPNCAR reanalysis (Kalnay et al. 1996). They consist of daily values (1200 UTC) of 1000- and 700-hPa geopotential heights (Z1000 and Z700, respectively) at 375 grid points $\left(2.5^{\circ} \times 2.5^{\circ}\right.$ spatial resolution $)$, encompassing an area from $5.0^{\circ}-40.0^{\circ} \mathrm{N}$ to $10.0^{\circ}-70.0^{\circ} \mathrm{E}$. Synoptic data are obtained for days identified as those of the DOs' onset (see the section 3) and preceding the event. The spatial resolution and extent of the atmospheric fields are chosen so that the synoptic-scale atmospheric features (i.e., the subtropical anticyclone extension to the Mediterranean, the Arabian Peninsula summer low, etc.) are adequately depicted.

\section{Methodology}

As a first step, the daily mean $\mathrm{AOD}_{500}$ values are used in order to identify DOs. The criterion for a DO occurrence is considered to be a day-to-day increase of the $\mathrm{AOD}_{500}$ by 0.3 . This value, according to the BeerLambert law, corresponds to a reduction of about $25 \%$ of the direct solar radiation at the wavelength of $500 \mathrm{~nm}$. The day for which the criterion is fulfilled is considered as the first day ( $D$ day) of the DO. The day preceding the $D$ day is labeled as $D-1$ day. The consequent analysis computes the duration of a DO based on the elapsed time from $D$ day until the $\mathrm{AOD}_{500}$ value reduces back to the value of $D-1$ day. Based on the aforementioned criteria, 177 DOs are identified and their duration is also determined. In addition, $D$ days' $\alpha_{440-870}$ values are examined and $99.5 \%$ of them are found to be less than 1 , ensuring that the $\mathrm{AOD}_{500}$ increase is due to dust presence in the atmosphere. It has been suggested that low values of $\alpha$ (less than $\sim 1$ ) correspond to the dominance of coarse particles (i.e., desert dust) in the atmosphere (Kubilay et al. 2003; Smirnov et al. 2002; Eck et al. 2008; Sabbah and Hasan 2008; Gkikas et al. 2009). The $\mathrm{AOD}_{500}$ values of $D-1$ and $D$ days of a $\mathrm{DO}\left(\mathrm{AOD}_{D-1}\right.$ and $\mathrm{AOD}_{D}$, respectively), along with the mean $\mathrm{AOD}_{500}\left(\mathrm{AOD}_{M}\right)$ throughout the duration of a DO are considered as its main intensity proxies. Similarly, the $\alpha_{440-870}$ value for the $D-1$ and $D$ days $\left(\alpha_{D-1}\right.$ and $\alpha_{D}$, respectively), along with the mean $\alpha_{440-870}\left(\alpha_{M}\right)$ throughout the duration of a DO are also calculated.

Note that the choice of the specific criterion of the DOs stems from the corresponding reduction of direct solar radiation at the wavelength of $500 \mathrm{~nm}$ by at least $25 \%$, which is important for the efficient operation of the installed photovoltaic power station. For instance, during a very strong dust event in March 2009 in Saudi Arabia, Maghrabi et al. (2011) estimated a direct radiative effect at the surface (decrease of direct downward solar radiation) of $68 \%$, whereas Kalenderski et al. (2013) reported an instantaneous surface dust radiative effect of $-205 \mathrm{~W} \mathrm{~m}^{-2}$.

The next step is the identification of the dominant types of the atmospheric circulation evolution (from $D-1$ to $D$ day) that favors the onset of DOs. For this purpose, factor analysis (Jolliffe 1986; Manly 1986) and cluster analysis (Sharma 1996), are applied on the atmospheric field data. A brief description of these two multivariate statistical methods is given in a previous study of Houssos and Bartzokas (2006). Figure 2 illustrates a schematic representation of the application of the two statistical methods in this study. In particular, two $177 \times 750$ matrices are constructed, the first one comprising the daily (at 1200 UTC) values of 1000- and $700-\mathrm{hPa}$ geopotential heights at 375 grid points for $D-1$ days and the second one for $D$ days of the 177 DOs. In these matrices each row corresponds to the Z1000 and Z700 fields in a given day, thus the atmospheric circulation in the lower troposphere on that day is described, while each column corresponds to the Z1000 and Z700 time series at each grid point.

On these two matrices factor analysis is applied in order to reduce the dimensionality of the data. For $D-1$ days the 750 time series of the 1000- and 700-hPa geopotential height are reduced to eight standardized (zero mean and unit variance) uncorrelated factors, which account for $86.7 \%$ of the total variance of the initial data matrix. To 


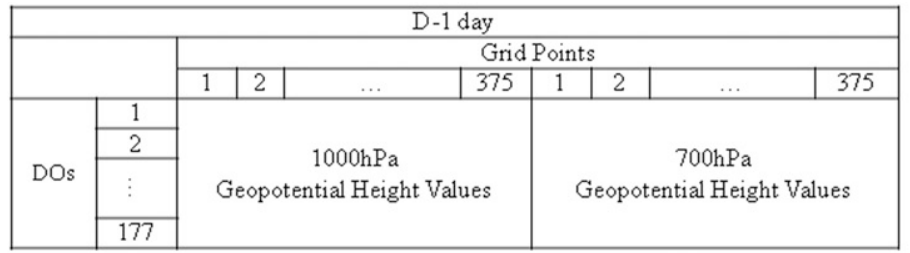

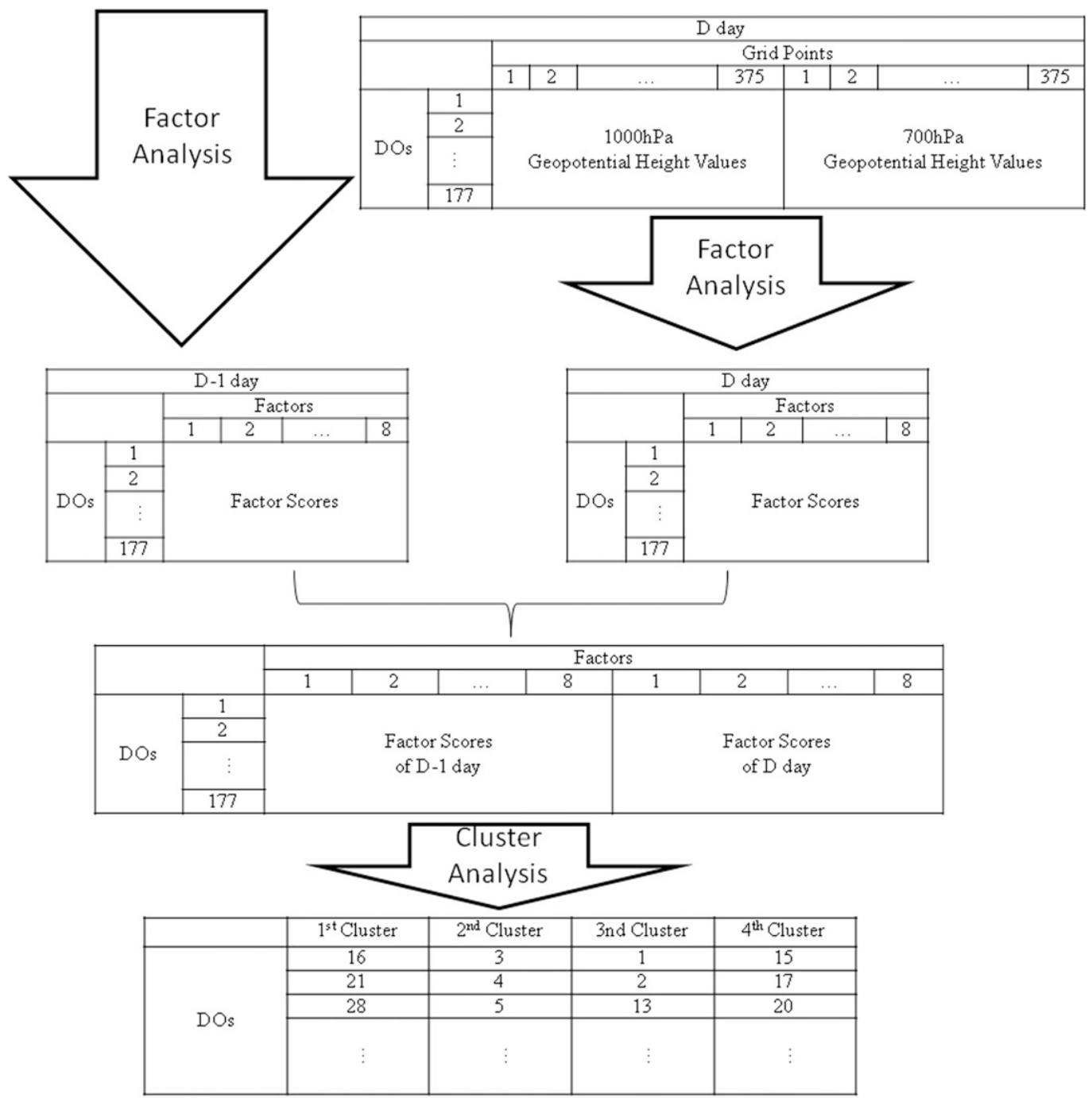

FIG. 2. The methodology scheme for the identification of the atmospheric circulation evolution types favoring the onset of dust outbreaks over Solar Village (central Saudi Arabia).

decide on the number of factors to be retained, the criterion is that those factors should account for at least $85 \%$ of the initial dataset's total variance (Jolliffe 1993) and have a physical interpretation, in terms of high (more than 0.5) factor loading values. The resulting eight uncorrelated factors correspond to eight subregions, that comprise grid points where the Z1000 and Z700 time series covariate in time with a characteristic mode. This way, the atmospheric circulation of each $D-1$ day is satisfactorily represented only by eight values, the factors score values, instead of 750 . For $D$ days the 750 time series of the 1000- and 700$\mathrm{hPa}$ geopotential height are also reduced to eight factors accounting for the $86.5 \%$ of the initial data matrix total variance. The detailed results of the factor analysis (loadings, factor scores, etc.) are not presented because the method is used only as a datareduction tool. 



FIG. 3. The intra-annual variation of the 177 DOs (a) mean monthly frequency and (b) their duration distribution. Also, the intra-annual variations of (c) mean monthly $\mathrm{AOD}_{D}$ and $\mathrm{AOD}_{M}$ and (d) mean monthly $\alpha_{D}$ and $\alpha_{M}$ for the 177 DOs.

These new $177 \times 8$ matrices for $D-1$ and $D$ days are then unified to form a $177 \times 16$ matrix. In this matrix in each row the first eight factor score values represent the atmospheric circulation on $D-1$ day and the next eight factor score values describe the atmospheric circulation on $D$ day. Thus, each row corresponds to the atmospheric circulation evolution from $D-1$ day to $D$ day, for a given DO. The $K$-means cluster analysis is applied on the unified matrix to objectively classify the 177 cases of the atmospheric circulation evolution into discrete and homogeneous clusters. For deciding the number of clusters to be retained, the distortion test (Sugar and James 2003) is employed whereas the ability of the results to receive a physical interpretation is also considered. It is found that the optimum number of clusters is 4 , so that each of them can be as homogeneous and discrete to the others as possible. Finally, for each cluster, mean patterns of Z1000 and Z700 for $D-1$ and $D$ days are plotted together with the mean patterns of the differences between $D$ and $D-1$ day, revealing the main types of the atmospheric circulation evolution at the lower troposphere, associated with the onset of DOs over Solar Village. To have a sense of the uncertainty of the aforementioned mean patterns, the respective standard deviation patterns are also plotted (see Figs. S1-S4 in the online supplemental material).

\section{Results and discussion}

\section{a. General characteristics of DOs}

Figure 3a illustrates the identified DOs' mean intraannual variation and further underlines that these events are more frequent from February to August, with an average frequency of $1.7 \mathrm{DOs} \mathrm{yr}^{-1} \mathrm{month}^{-1}$ and a maximum frequency of $2.3 \mathrm{DOs} \mathrm{yr}^{-1}$ in May. Overall, the spring and summer seasons relate to the highest DO frequency as opposed to the relatively colder season. Along these lines, our results indicate that the mean monthly $\mathrm{AOD}_{500}$ values (i.e., $\mathrm{AOD}_{D}$ and $\mathrm{AOD}_{M}$ ) exhibit a maximum $(1.2 \pm 0.4$ and $1.1 \pm 0.5$, respectively) during June (Fig. 3c), implying that DOs are more frequent in May but more intense in June. Besides, $\alpha$ exhibits its lowest values $\left(\sim 0.09\right.$ for the mean monthly $\alpha_{D}$ and $\alpha_{M}$ ) in March for $\alpha_{D}$ and in May and June for $\alpha_{M}$ (Fig. 3d), ensuring that the high AOD values are due to dust presence in the atmosphere. The occurrence of 


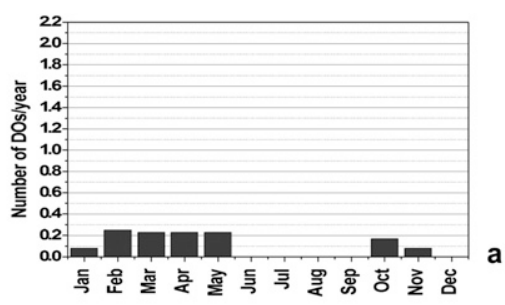

Day D-1


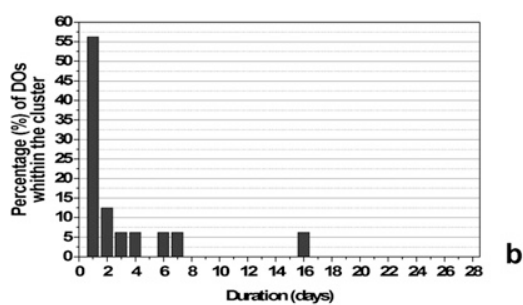

Day D
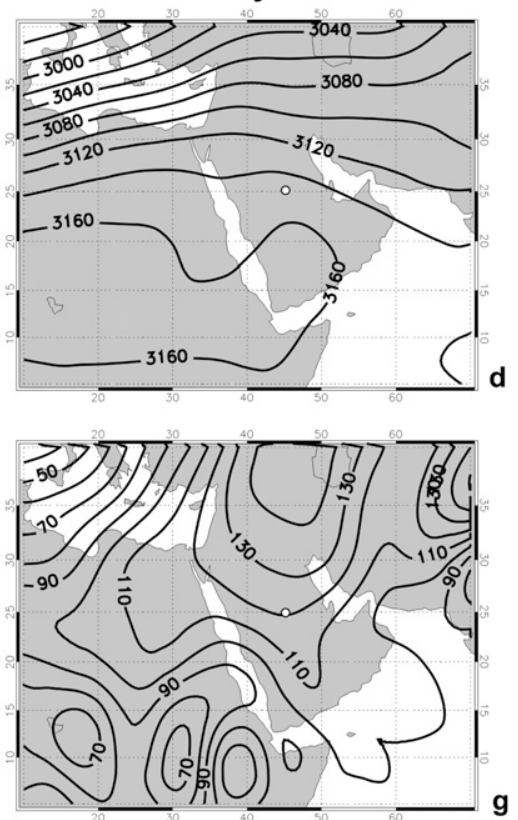

\section{Cluster 1 (16 DOs)}

$\begin{array}{ccc}\text { AODD-1 } & \text { AODo } & \text { AODM } \\ 0.3 \pm 0.1 & 0.7 \pm 0.3 & 0.7 \pm 0.3\end{array}$

$\underset{0.40 \pm 0.34}{\alpha_{\mathrm{D}-1}} \underset{0.09 \pm 0}{\alpha_{\mathrm{D}}} \quad \boldsymbol{\alpha}_{\mathrm{M}}$

$0.40 \pm 0.34 \quad 0.09 \pm 0.12 \quad 0.09 \pm 0.11$
Day to Day Difference (D Minus D-1)
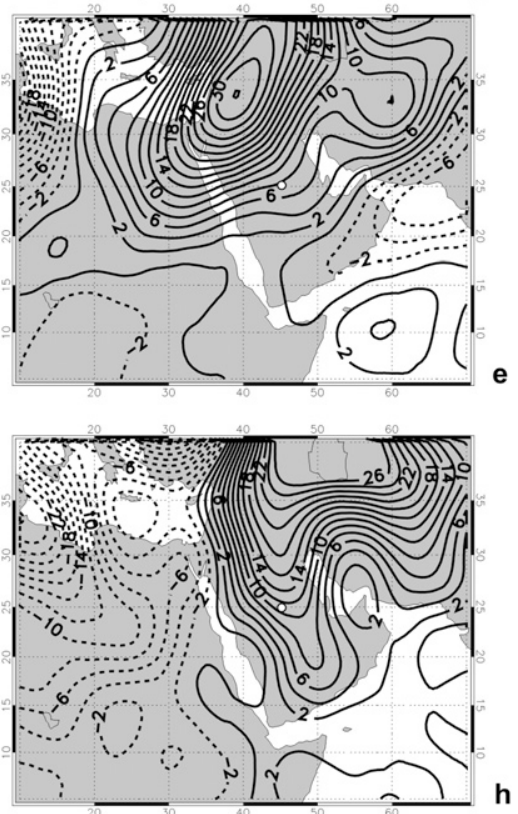

FIG. 4. For cluster 1 (16 DOs), (a) the intra-annual variation of the mean monthly frequency of the 16 DOs classified in this cluster, (b) their duration distribution, and (top right) the mean values \pm standard deviations of AOD for $D-1, D$ day, and during the DOs $\left(\mathrm{AOD}_{D-1}, \mathrm{AOD}_{D}\right.$, and $\mathrm{AOD}_{M}$, respectively) showing DOs intensity and of $\alpha$ for $D-1, D$ day, and during the DOs $\left(\alpha_{D-1}, \alpha_{D}\right.$, and $\alpha_{M}$, respectively) showing dust presence in the atmosphere. The mean atmospheric circulation on (c) $D-1$, (d) $D$ day, and (e) the day-to-day differences ( $D$ minus $D-1$ ) at the 700-hPa level (in gpm). Also, the mean atmospheric circulation on (f) $D-1$, (g) $D$ day, and (h) the dayto-day differences $(D$ minus $D-1)$ at the 1000 -hPa level (in gpm). The white open circle denotes the Solar Village location.

maximum dust storm intensity is in agreement with the findings of other researches (e.g., Smirnov et al. 2002; Prospero et al. 2002; Kutiel and Furman 2003, and references therein). The DO duration exhibits a lognormal distribution (Fig. 3b). Almost half of the 177 identified DOs $(\sim 45 \%)$ lasted for 1 day, while $18 \%$ of them lasted for 2 days. During the 12-yr study period, only 6 DOs $(\sim 3 \%)$ exhibited duration longer than 10 days.

\section{b. Atmospheric circulation types associated with DOs}

\section{1) Cluster 1 (16 CAses, 9\%)}

The majority $(75 \%)$ of the DOs grouped under this cluster occurred between February and May (Fig. 4a). Approximately half $(56 \%)$ of this cluster's DOs exhibited a duration of 1 day, while the remaining extended up to 7 days with the exception of a single DO that lasted for 16 consecutive days (Fig. 4b). The mean
$\mathrm{AOD}_{D}$ is computed as $0.7 \pm 0.3$, the lowest among all the identified four clusters. However, the low $\alpha_{D}$ mean value $(0.09 \pm 0.12)$ denotes the predominance of coarse particles in the atmosphere. The mean $\mathrm{AOD}_{D-1}$ is also among the lowest $(0.3 \pm 0.1)$ in our database.

The atmospheric circulation at Z700 during $D-1$ day is approximately zonal in the northern part of the Arabian Peninsula, Syria, Iraq, and Iran, while there is evidence of a weak pressure trough over the Red Sea (Fig. 4c). This trough is associated with the cyclonic circulation at Z1000 over eastern Africa and the southwestern Arabian Peninsula (Fig. 4f). To the northwest (i.e., the Arabian Peninsula and the Middle East) the anticyclonic circulation near the surface most likely favors weak wind conditions, supporting the previously highlighted $D-1$ day's low aerosol load regime. During $D$ day, this anticyclonic circulation over the Middle East becomes more pronounced, evident at both the Z700 and Z1000 levels (Figs. 4d 


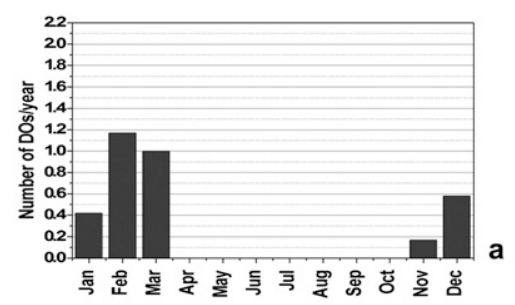
Day D-1
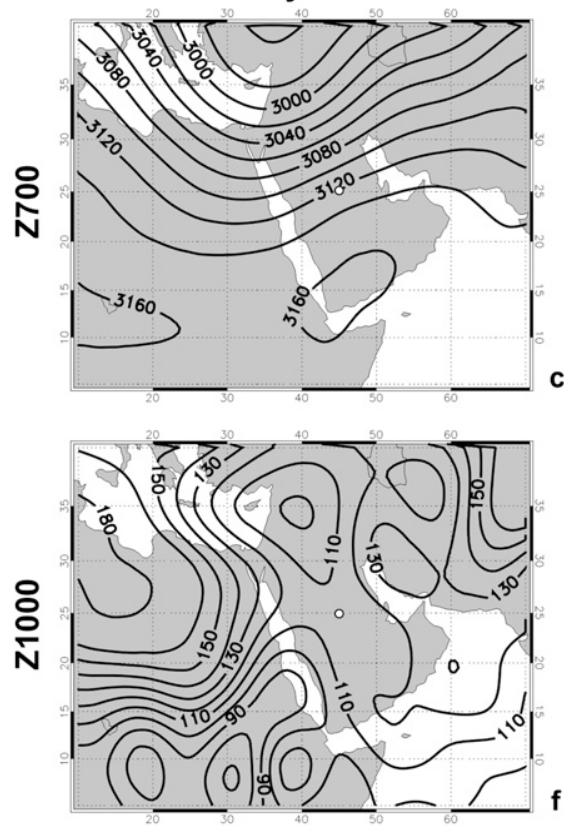

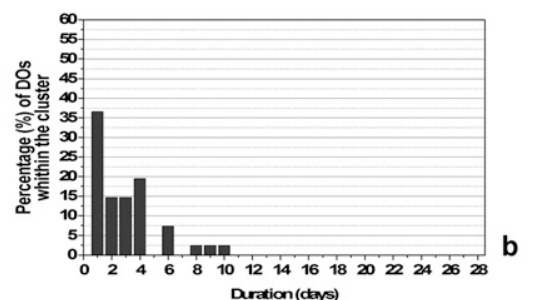

Day D
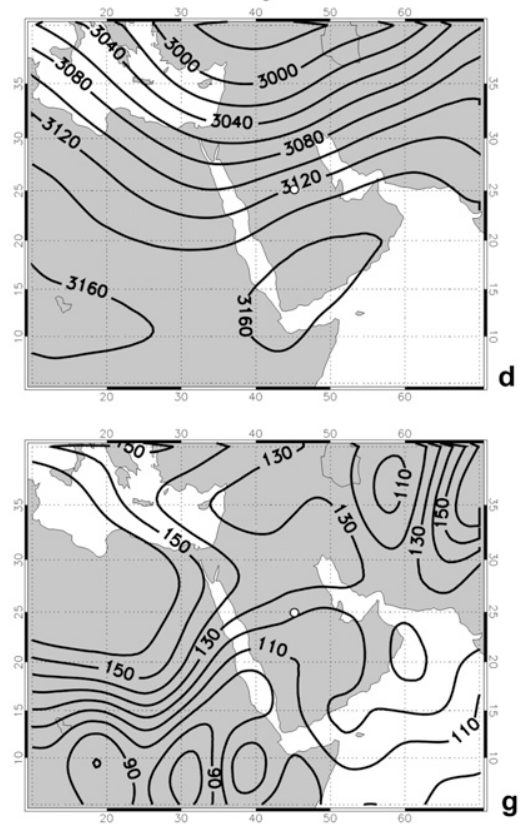

\section{Cluster 2 (41 DOs)}

$\begin{array}{ccc}\text { AOD }_{\mathrm{D}-1} & \text { AOD }_{\mathrm{D}} & \text { AOD }_{\mathrm{M}} \\ 0.3 \pm 0.2 & 0.9 \pm 0.4 & 0.7 \pm 0.4 \\ & & \\ \boldsymbol{\alpha}_{\mathrm{D}-1} & \boldsymbol{\alpha}_{\mathrm{D}} & \boldsymbol{\alpha}_{\mathrm{M}} \\ 0.49 \pm 0.34 & 0.15 \pm 0.18 & 0.18 \pm 0.19\end{array}$

Day to Day Difference (D Minus D-1)
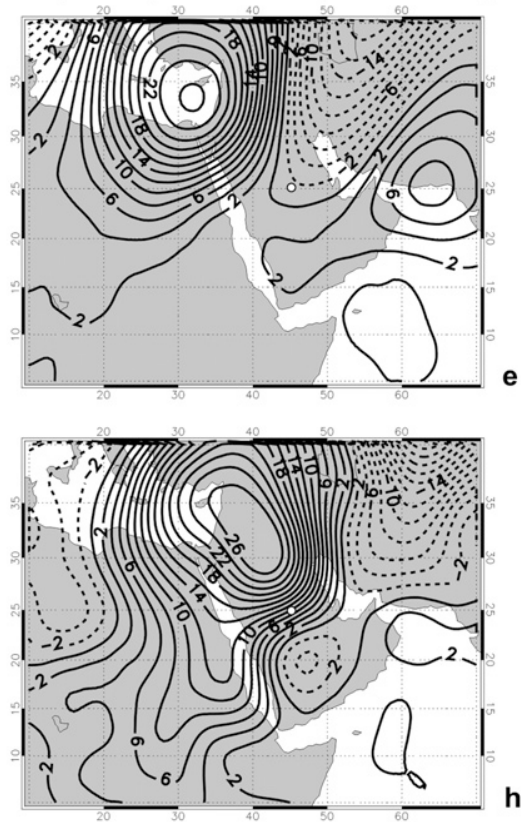

FIG. 5. As in Fig. 4, but for cluster 2 (41 DOs).

and $4 \mathrm{~g}$ ). At the Z1000 level, the anticyclone intensifies exhibiting an overall 10-20-gpm increase accompanying the geopotential height gradient (i.e., pressure gradient) strengthening over the central Arabian Peninsula. These results suggest that the weak day-to-day differences $(\sim 2 \mathrm{gpm})$ over the southeastern Arabian Peninsula along with the higher differences ( 12-16 gpm) over the northern Arabian Peninsula lead to the increase of the pressure gradient over the region (Fig. 4h). These synoptic conditions induce a north-northeast surface flow over the Persian Gulf and central Saudi Arabia, favoring DOs in the region. This northerly airflow is documented by Wilkerson (1991, p. 7) described as "a narrow tongue of cold, dry and gusty winds" causing the uplift of the relatively warmer air ahead of it and the consequent uplift of dust in the atmosphere. The author also indicates that the above can be seen as a rare case of winter Shamal, not associated with the typical frontal systems.

\section{2) Cluster 2 (41 CASEs, 23\%)}

The DOs in this cluster occurred during the cold season (November-March, Fig. 5a) with a maximum frequency of $1.2 \mathrm{DOsyr}^{-1}$ during February. As it is shown in Fig. $5 b$ the majority of the DOs $(\sim 56 \%)$ last between 2 and 6 days. The mean $\mathrm{AOD}_{D}$ value is computed as $0.9 \pm 0.4$ and given the significantly lower mean $\mathrm{AOD}_{D-1}(0.3 \pm 0.2)$, one could argue that DOs in this cluster are rather violent ( $\mathrm{AOD}_{500}$ increase of $\sim 200 \%$ ). The large difference between the mean values of $\alpha_{D-1}$ $(0.49 \pm 0.34)$ and $\alpha_{D}(0.15 \pm 0.18)$, along with the low value of $\alpha_{D}$ further supports the sudden appearance of coarse dust particles in the atmosphere.

At the Z700 level, the pressure trough over northeastern Africa and the eastern Mediterranean is propagating eastward (Figs. 5c,d). This observation is also corroborated by the day-to-day differences at the Z700 field (Fig. 5e), where it becomes evident that the 700$\mathrm{hPa}$ geopotential height during $D$ day decreases over northern Iran and increases over the eastern Mediterranean and northern Africa.

Near the surface (Z1000) a depression associated with the Z700 trough propagates eastward, crossing over the Middle East on day $D-1$ to northeastern Iran on day $D$ (Figs. 5f,g). Also on day $D$, a weaker depression is 




Day D-1
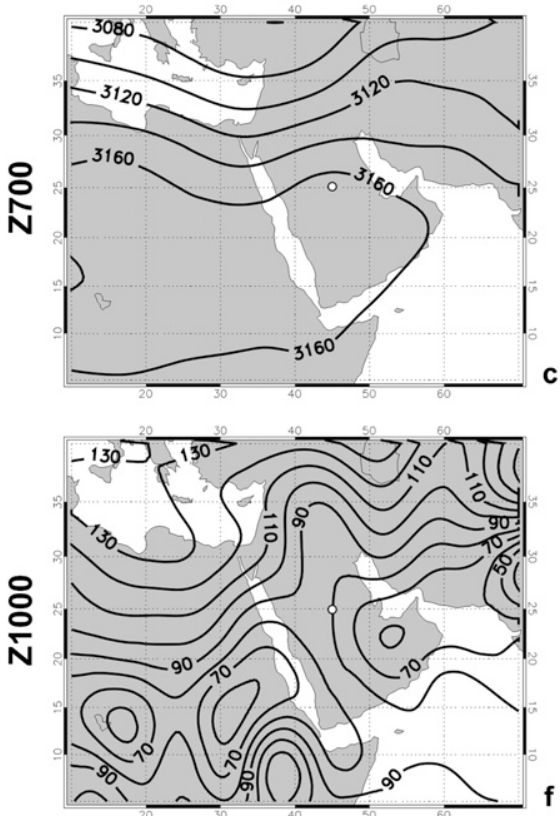

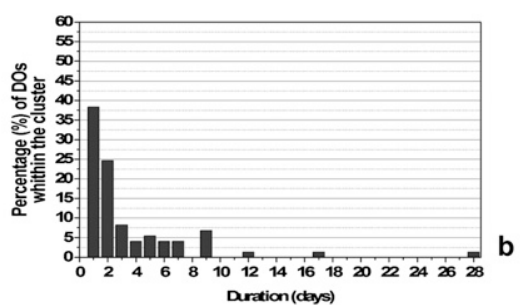

Day D



Day to Day Difference (D Minus D-1)
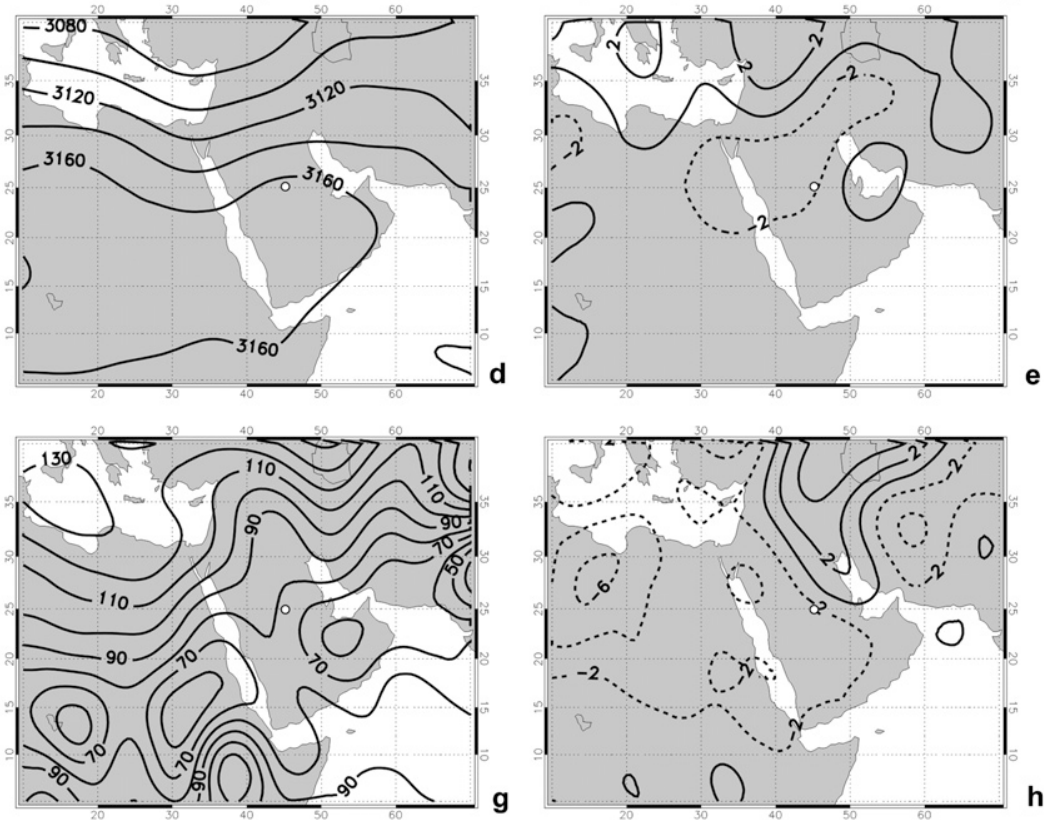

FIG. 6. As in Fig. 4, but for cluster 3 (73 DOs).

evident over the southern Arabian Peninsula. The synoptic conditions on day $D$ exhibit a northerly airflow at the surface that can be characterized as a typical winter Shamal. The atmospheric circulation related to this cluster is in agreement with the description of the winter Shamal by Perrone (1979) and Rao et al. (2001). During winter, depressions originating from the eastern Mediterranean and crossing over the Middle East are accompanied by fronts, giving rise to northerly winds able to induce intense DOs over the Middle East and the Arabian Peninsula.

\section{3) Cluster 3 (73 CAses, $41 \%$ )}

This cluster, relative to the others, encompasses the highest number (73) of the identified DOs. These DOs occur from March to June, with a maximum frequency (2.1 DOs yr ${ }^{-1}$ ) during May (Fig. 6a). A total of $63 \%$ of the DOs exhibited durations of 1-2 days, while the remaining extended up to 9 days (Fig. 6b). The DO with the highest duration in the database (28 days) was classified under this cluster. In addition to their long duration, the associated intensity proxies are indicative of their high intensity (mean $\mathrm{AOD}_{D}=1.1 \pm 0.4$ and mean $\mathrm{AOD}_{M}=1.1 \pm 0.4$ ).
The DOs of this cluster are coincident with the transitional season of the year, characterized by a variety of synoptic conditions with the onset of the Indian monsoon (Fig. 6). Near the surface during $D-1$ day (Fig. 6f) the signature of the monsoon is evident. More specifically, the cyclonic circulation at the Z1000 level over the southeastern Arabian Peninsula is related to the onset of a thermal low pressure system over the same region, known as the Arabian Peninsula summer low, associated with thermal convection, instability, and thus turbulent conditions and local dust suspension near the surface. Note that on $D-1$ day mean $\mathrm{AOD}_{D-1}$ and $\alpha_{D-1}$ are equal to $0.5 \pm 0.3$ and $0.24 \pm$ 0.21 , respectively, indicating that the atmospheric dust load is already high one day before the initiation of the DOs. In addition, the pressure gradient developed between the Arabian Peninsula thermal low and the higher pressures (i.e., higher geopotential heights) over Iraq and western Iran, being the southward extension of the Caspian anticyclone, induces a northeasterly airflow over the Persian Gulf, bringing humidity to the central Saudi Arabia. The combination 

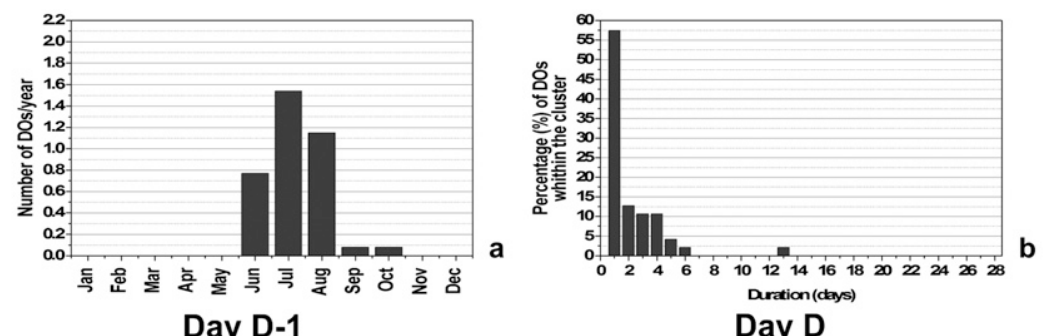

Cluster 4 (47 DOs)

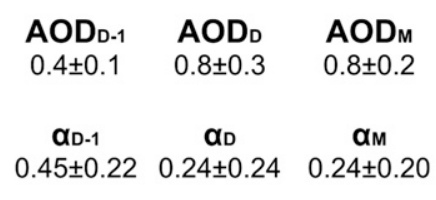

Day D
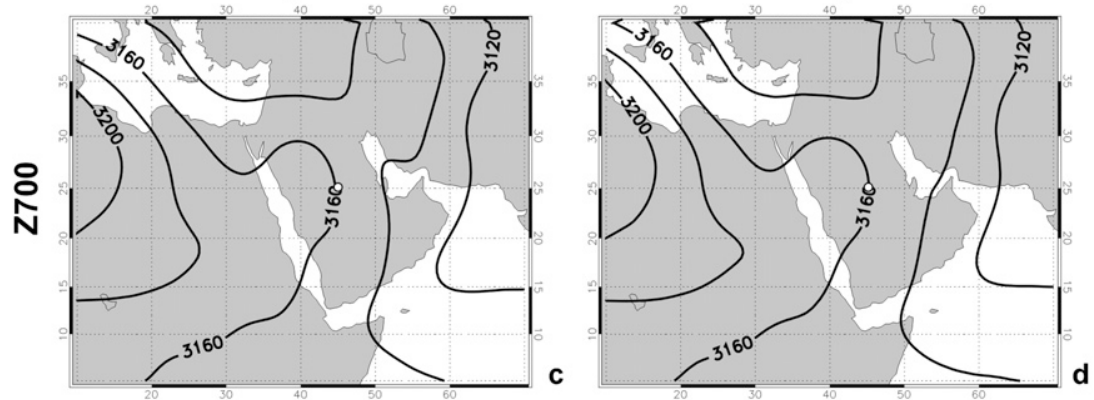

Day to Day Difference (D Minus D-1)
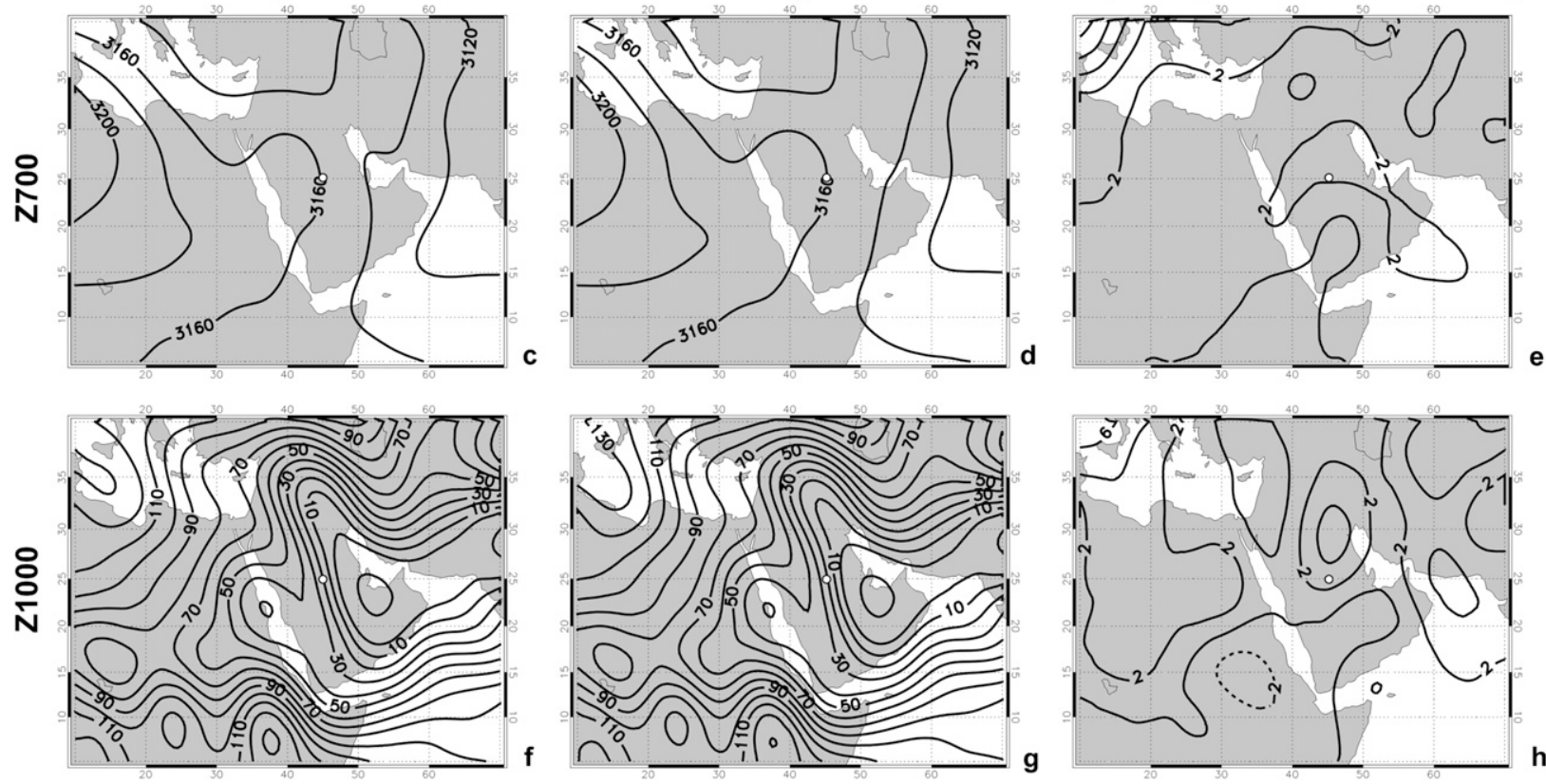

FIG. 7. As in Fig. 4, but for cluster 4 (47 DOs).

of increased moisture content with thermal convection favors convective storm development, the downdrafts of which are responsible for strong Haboob dust storms. Furthermore, under the appropriate forcing of the upper-troposphere dynamics, namely the eastward advance of a narrow jet streak, near the surface a trough is formed over the northern Arabian Peninsula (Fig. 6g), inducing a strong northerly flow advecting dust over the study region. For two dust storm cases (a Haboob and a jet streak case) Alharbi (2008) described the associated synoptic conditions that are similar to the atmospheric circulation during $D$ day in the lower troposphere (Fig. 6d) and near the surface (Fig. 6g). These dust storm cases are also identified as DOs by the criterion used in the present study and their associated atmospheric circulation evolutions are both classified in this cluster.

\section{4) Cluster 4 (47 CASES, 27\%)}

The DOs classified in this cluster occurred mostly during the summer months with maximum frequency of 1.5 DOs yr ${ }^{-1}$ in July (Fig. 7a). More than half ( $\left.\sim 57 \%\right)$ of the DOs have a duration of 1 day and the remaining extend up to 6 days (Fig. 7b). Their intensity is moderate compared to other clusters, with the mean $\mathrm{AOD}_{D}$ and $\mathrm{AOD}_{M}$ computed equal to $0.8 \pm 0.3$ and $0.8 \pm 0.2$, respectively, and the mean $\alpha_{D}$ and $\alpha_{M}$ found to be $0.24 \pm$ 0.24 and $0.24 \pm 0.20$, respectively.

The DOs encompassed by this cluster relate to the typical summer Shamal conditions (Fig. 7). The dominant atmospheric circulation features near the surface (Figs. 7f,g) are as follows: 1) a deep depression over southern Iran and the southeastern Arabian Peninsula, which is associated with the massive westward expansion of the Indian monsoon thermal low; and 2) anticyclonic circulation over the Mediterranean basin and North Africa, related to the subtropical pressure high, extending eastward over northwestern Saudi Arabia. At upper levels (Figs. 7c,d) anticyclonic circulation prevails over the largest part of the Arabian Peninsula while the monsoon trough seems to preserve its pattern. The dominant east-west geopotential height gradient near the surface, (i.e., the pressure gradient between the aforementioned thermal low and subtropical high), results in an approximately northerly surface flow (the 
Shamal winds) over the Arabian Peninsula. The Shamal winds blow with speeds of about $15-20 \mathrm{~m} \mathrm{~s}^{-1}$ (Rao et al. 2003; Alharbi 2008) lifting up and transporting large amounts of dust. As a result, the dust originates not only from local sources but also from sources in northern regions such as the An Dafun and Syrian deserts as well as desert regions in western and southern Iraq (Mohalfi et al. 1998; Rao et al. 2003; Hamidi et al. 2013). It is worth noting that the atmospheric circulation indicated by both Z1000 and Z700, does not exhibit significant differences from $D-1$ to $D$ day (Figs. 7e,h). Instead, a persistence of the meridional (northerly) flow at Z700 and the strong northwesterly Shamal wind at the surface is evident. This is somewhat expected since this pattern corresponds to a period during which the Indian monsoon is well established and exhibits its most active phase (Tyrlis et al. 2013). Nevertheless, the onset of DOs appears to be controlled by the strengthening of the subtropical anticyclone prevailing over the Mediterranean and North Africa (positive differences of geopotential height over these regions, shown in Fig. 7h). This intensification is accompanied by a slight expansion toward central Saudi Arabia increasing the east-west pressure gradient and therefore reinforcing the Shamal winds (Fig. $7 \mathrm{~g}$ ). The slight weakening of the northwestern extension of the trough over Iraq implies that the DOs are not triggered by the deepening of this trough or of the thermal low over southeastern Saudi Arabian. The DOs related to this cluster's geopotential height patterns are summarized by a synoptic-scale mechanism whereas local thermodynamical characteristics can also play an important role in the onset of a DO. For instance, Alharbi (2008) analyzing two Shamal dust storm cases in Riyadh during the summer 2006 found that the strongest Shamal events are associated with a confined boundary layer due to low air moisture content, which limits the vertical mixing processes and thus the boundary layer development inducing a strong low-level Shamal flow.

5) STANDARD DEVIATION PATTERNS OF THE Z1000 AND Z700 MEAN PATTERNS

To have a sense of the uncertainty of all the above described mean patterns, for each cluster and for each atmospheric level (Z700 and Z1000) mean patterns of $D-1$ and $D$ days, the respective standard deviation pattern was plotted (not shown) and examined.

It is found that for all clusters and for both atmospheric parameters (Z700 and Z1000) the standard deviation patterns of $D-1$ and $D$ days present a great resemblance. Thus only $D$ day's standard deviation patterns will be discussed.

For the Z700 standard deviation patterns it is found that values vary from around 70 to $10 \mathrm{gpm}$ for clusters
1 and 2, while for clusters 3 and 4 they range from around 50 to $10 \mathrm{gpm}$. In all clusters high/low values of standard deviation are found in the northern/southern regions of the study area.

For cluster 1 in the $D$ days' Z1000 standard deviation pattern relatively high values of standard deviation ( $\sim 40 \mathrm{gpm})$ are found over the northern Arabian Peninsula, where the anticyclonic circulation intensifies on $D$ day, contributing to DOs' onset. Such high standard deviation values imply that this intensification of the anticyclonic circulation over the northern Arabian Peninsula can be either weaker or stronger than it is depicted in $D$ days' Z1000 mean pattern (Fig. 4g), but still remains the main controlling factor leading to DOs.

For cluster 2, a strip of high standard deviation values (45-30 gpm) extends from the northern to southern Arabian Peninsula, over the same regions where the depressions favoring northerly winds and therefore DOs, are depicted in $D$ days' Z1000 mean pattern. These comparatively high standard deviation values imply that in some cases of DOs, classified in this cluster, the depressions are shallower and in other cases are deeper than depicted in the $D$ days' Z1000 mean pattern (Fig. $5 \mathrm{~g}$ ). Furthermore, these high standard deviations could also be attributed to the possible slight differentiation of the depressions' location from case to case.

For cluster 3 relatively high standard deviations $(\sim 40 \mathrm{gpm})$ are observed over western Iran. This implies that the strength of the southward extension of the Caspian anticyclone over that region, which in combination with the Arabian Peninsula summer low favors the advection of humid air masses over the Solar Village, can greatly vary among the DOs' cases.

For cluster 4, the low standard deviation values (15$25 \mathrm{gpm}$ ) over the Mediterranean and northern Africa and the relatively moderate standard deviation values ( $\sim 25 \mathrm{gpm})$ over the southeastern Arabian Peninsula imply that during summer the subtropical high extension over the Mediterranean and the monsoonal atmospheric circulation over the southeastern Arabian Peninsula are well established.

\section{Conclusions}

For a 12-yr period spanning from 1999 to 2011, 177 DOs are identified from the Solar Village AERONET station (central Saudi Arabia), based on the day-to-day increase of $\mathrm{AOD}_{500}$ by 0.3 and also by taking into consideration that the values of the Angström exponent should be low, to ensure dust presence in the atmosphere. A reduction of $\mathrm{AOD}_{500}$ by 0.3 is directly related to a reduction of direct solar radiation by approximately 
$25 \%$. Thus, the criterion in use quantifies the effects of DOs on the efficiency of solar power exploitation by the Photovoltaic Power System operating in Solar Village. The implementation of factor and cluster analysis at the 1000- and 700-hPa geopotential height daily patterns of the day preceding the onset of the DOs and the day of their initiation reveals four main types of atmospheric circulation evolution. During winter, the presence of anticyclonic circulation over the Arabian Peninsula enhances the DO occurrence over Solar Village due to the strengthening of the pressure gradient and the consequent northerly airflow over the study region (cluster 1). Also during winter the majority of DOs can be attributed to the passage of midlatitude depressions through the Middle East, causing postfrontal northerly winds (cluster 2). During summer, the dominant pressure gradient over the Middle East and the Arabian Peninsula driven by the Persian trough over the southeastern Arabian Peninsula and the extension of the Azores anticyclone over the Mediterranean, leads to the formation of the Shamal winds. The onset of the DOs is more likely controlled by the intensification of high pressure over the Mediterranean (cluster 4) and given the available literature the latter may be further controlled by the North Atlantic Oscillation (Chronis et al. 2011). On the contrary, the DOs occurring during the onset phase of the monsoon (April-June) are strongly affected by the thermal trough characteristics and the dynamics of the upper troposphere (cluster 3).

The findings of the present research work can be a useful tool to forecasters. The comprehensive presentation of the main atmospheric circulation evolution types that favor the onset of dust outbreaks in the central Arabian Peninsula can promote an improved forecasting of such events. Furthermore, the knowledge of (i) the synoptic conditions under which DOs in central Saudi Arabia are likely to occur, (ii) DO temporal and intensity characteristics, and (iii) the quantification of DO effects on solar power exploitation can contribute to the better planning as well as risk analysis of the photovoltaic plants operation in the region.

Acknowledgments. The authors wish to heartily thank Dr. John Christy, Director of the Earth System Science Center at the University of Alabama, for his financial support.

\section{REFERENCES}

Abdi Vishkaee, F., C. Flamant, J. Cuesta, P. Flamant, and H. R. Khalesifard, 2011: Multiplatform observations of dust vertical distribution during transport over northwest Iran in the summertime. J. Geophys. Res., 116, D05206, doi:10.1029/ 2010JD014573.
- - L. Oolman, P. Flamant, and H. R. Khalesifard, 2012: Dust transport over Iraq and northwest Iran associated with winter Shamal: A case study. J. Geophys. Res., 117, D03201, doi:10.1029/2011JD016339.

Alawaji, S. H., 2001: Evaluation of solar energy research and its applications in Saudi Arabia-20 years of experience. Renewable Sustain. Energy Rev., 5, 59-77, doi:10.1016/ S1364-0321(00)00006-X.

Alharbi, B. H., 2008: Airborne dust in Saudi Arabia: Source areas, entrainment, simulation and composition. Ph.D. thesis, Monash University, Victoria, Australia, 313 pp.

— A. Maghrabi, and N. Tapper, 2013: The March 2009 dust event in Saudi Arabia. Bull. Amer. Meteor. Soc., 94, 515-528, doi:10.1175/BAMS-D-11-00118.1.

Barkan, J., H. Kutiel, and P. Alpert, 2004: Climatology of dust sources in North Africa and the Arabian Peninsula, based on TOMS data. Indoor Built Environ., 13, 407-419, doi:10.1177/ 1420326 X04046935.

Christopher, S. A., and J. Zhang, 2002: Shortwave aerosol radiative forcing from MODIS and CERES observations over the oceans. Geophys. Res. Lett., 29, 1859, doi:10.1029/2002GL014803.

Chronis, T., D. Raitsos, and D. Kassis, 2011: The summer North Atlantic Oscillation effect on eastern Mediterranean. J. Climate, 24, 5584-5596, doi:10.1175/2011JCLI3839.1.

de Villiers, M. P., and J. van Heerden, 2007: Dust storms and dust at Abu Dhabi international airport. Weather, 62, 339-343, doi:10.1002/wea.42.

Eck, T. F., and Coauthors, 2008: Spatial and temporal variability of column-integrated aerosol optical properties in the southern Arabian Gulf and United Arab Emirates in summer. J. Geophys. Res., 113, D01204, doi:10.1029/2007JD008944.

Ghasem, A., Ali Akbar Shamsipour, M. Miri, and T. Safarrad, 2012: Synoptic and remote sensing analysis of dust events in southwestern Iran. Nat. Hazards, 64, 1625-1638, doi:10.1007/ s11069-012-0328-9.

Ginoux, P., D. Garbuzov, and N. C. Hsu, 2010: Identification of anthropogenic and natural dust sources using Moderate Resolution Imaging Spectroradiometer (MODIS) Deep Blue level 2 data. J. Geophys. Res., 115, D05204, doi:10.1029/ 2009JD012398.

— J. M. Prospero, T. E. Gill, N. C. Hsu, and M. Zhao, 2012: Global-scale attribution of anthropogenic and natural dust sources and their emission rates based on MODIS Deep Blue aerosol products. Rev. Geophys., 50, RG3005, doi:10.1029/ 2012RG000388.

Gkikas, A., N. Hatzianastassiou, and N. Mihalopoulos, 2009: Aerosol events in the broader Mediterranean basin based on 7-year (2000-2007) MODIS C005 data. Ann. Geophys., 27, 3509-3522, doi:10.5194/angeo-27-3509-2009.

Hamidi, M., M. R. Kavianpour, and Y. Shao, 2013: Synoptic analysis of dust storms in the Middle East. Asia Pac. J. Atmos. Sci., 49, 279-286, doi:10.1007/s13143-013-0027-9.

Holben, B. N., and Coauthors, 1998: AERONET-A federated instrument network and data archive for aerosol characterization. Remote Sens. Environ., 66, 1-16, doi:10.1016/ S0034-4257(98)00031-5.

— matology: Aerosol optical depth from AERONET. J. Geophys. Res., 106, 12 067-12 097, doi:10.1029/2001JD900014.

Houssos, E. E., and A. Bartzokas, 2006: Extreme precipitation events in NW Greece. Adv. Geosci., 7, 91-96, doi:10.5194/adgeo-7-91-2006.

Huang, J., C. Zhang, and J. M. Prospero, 2010: African dust outbreaks: A satellite perspective of temporal and spatial variability 
over the tropical Atlantic Ocean. J. Geophys. Res., 115, D05202, doi:10.1029/2009JD012516.

Jolliffe, I. T., 1986: Principal Component Analysis. Springer, 489 pp.

_- 1993: Principal component analysis: A beginner's guide. II. Pitfalls, myths and extensions. Weather, 48, 246-253, doi:10.1002/ j.1477-8696.1993.tb05899.x.

Kalenderski, S., G. Stenchikov, and C. Zhao, 2013: Modeling a typical winter-time dust event over the Arabian Peninsula and the Red Sea. Atmos. Chem. Phys., 13, 1999-2014, doi:10.5194/ acp-13-1999-2013.

Kalnay, E., and Coauthors, 1996: The NCEP/NCAR 40-Year Reanalysis Project. Bull. Amer. Meteor. Soc., 77, 437-471, doi:10.1175/1520-0477(1996)077<0437:TNYRP>2.0.CO;2.

Kim, D., M. Chin, H. Yu, T. F. Eck, A. Sinyuk, A. Smirnov, and B. N. Holben, 2011: Dust optical properties over North Africa and Arabian Peninsula derived from the AERONET dataset. Atmos. Chem. Phys., 11, 10 733-10 741, doi:10.5194/acp-11-10733-2011.

Krishnamurti, T. N., B. Jha, J. Prospero, A. Jayaraman, and V. Ramanathan, 1998: Aerosol and pollutant transport and their impact on radiative forcing over the tropical Indian Ocean during the January-February 1996 pre-INDOEX cruise. Tellus, 50B, 521-542, doi:10.1034/j.1600-0889.1998.00009.x.

Kubilay, N., T. Cokacar, and T. Oguz, 2003: Optical properties of mineral dust outbreaks over the northeastern Mediterranean. J. Geophys. Res., 108, 4666, doi:10.1029/2003JD003798.

Kutiel, H., and H. Furman, 2003: Dust storms in the Middle East: Sources of origin and their temporal characteristics. Indoor Built Environ., 12, 419-426, doi:10.1177/1420326X03037110.

Lau, K. M., and K. M. Kim, 2007: Cooling of the Atlantic by Saharan dust. Geophys. Res. Lett., 34, L23811, doi:10.1029/ 2007 GL031538.

Maghrabi, A., B. Alharbi, and N. Tapper, 2011: Impact of the March 2009 dust event in Saudi Arabia on aerosol optical properties, meteorological parameters, sky temperature and emissivity. Atmos. Environ., 45, 2164-2173, doi:10.1016/j.atmosenv.2011.01.071.

Manly, B. F. J., 1986: Multivariate Statistical Methods: A Primer. Chapman \& Hall, 224 pp.

Middleton, N. J., 1986: Dust storms in the Middle East. J. Arid Environ., 10, 83-96.

Miller, S. D., A. P. Kuciauskas, M. Liu, Q. Ji, J. S. Reid, D. W. Breed, A. L. Walker, and A. Al Mandoos, 2008: Haboob dust storms of the southern Arabian Peninsula. J. Geophys. Res., 113, D01202, doi:10.1029/2007JD008550.

Mohalfi, S., H. S. Bedi, T. N. Krishnamurti, and S. D. Cocke, 1998: Impact of shortwave radiative effects of dust aerosols on the summer season heat low over Saudi Arabia. Mon. Wea. Rev., 126, 3153-3168, doi:10.1175/1520-0493(1998)126<3153: IOSREO $>2.0 . \mathrm{CO} ; 2$

Muhs, D. R., J. R. Budahn, J. M. Prospero, and S. N. Carey, 2007: Geochemical evidence for African dust inputs to soils of western Atlantic islands: Barbados, the Bahamas, and Florida. J. Geophys. Res., 112, F02009, doi:10.1029/2005JF000445.

Pease, P. P., V. P. Tchakerian, and N. W. Tindale, 1998: Aerosols over the Arabian Sea: Geochemistry and source areas for aeolian desert dust. J. Arid Environ., 39, 477-496, doi:10.1006/ jare.1997.0368.

Perrone, T. J., 1979: Winter shamal in the Persian Gulf. Naval Environmental Prediction Research Facility Tech. Rep. 79-06, 168 pp.

Prospero, J. M., P. Ginoux, O. Torres, S. E. Nicholson, and T. E. Gill, 2002: Environmental characterization of global sources of atmospheric soil dust identified with the Nimbus 7 Total Ozone Mapping Spectrometer (TOMS) absorbing aerosol product. Rev. Geophys., 40, 1002, doi:10.1029/2000RG000095.

Rajeev, K., V. Ramanathan, and J. Meywerk, 2000: Regional aerosol distribution and its long-range transport over the Indian Ocean. J. Geophys. Res., 105, 2029-2043, doi:10.1029/ 1999JD900414.

Ramanathan, V., and Coauthors, 2001: The Indian Ocean Experiment: An integrated analysis of the climate forcing and effects of the great Indo-Asian haze. J. Geophys. Res., 106, 2837128 398, doi:10.1029/2001JD900133.

Rao, P. G., M. Al-Sulaiti, and A. H. Al-Mulla, 2001: Winter shamals in Qatar, Arabian Gulf. Weather, 56, 444-451, doi:10.1002/ j.1477-8696.2001.tb06528.x.

— , H. R. Hatwar, M. Al-Sulaiti, and A. H. Al-Mulla, 2003: Summer shamals over the Arabian Gulf. Weather, 58, 471-478, doi:10.1002/wea.6080581207.

Rezazadeh, M., P. Irannejad, and Y. Shao, 2013: Climatology of the Middle East dust events. Aeolian Res., 10,103-109, doi:10.1016/ j.aeolia.2013.04.001.

Sabbah, I., and F. M. Hasan, 2008: Remote sensing of aerosols over the Solar Village, Saudi Arabia. Atmos. Res., 90, 170-179, doi:10.1016/j.atmosres.2008.02.004.

Shao, Y., and Coauthors, 2011: Dust cycle: An emerging core theme in Earth system science. Aeolian Res., 2, 181-204, doi:10.1016/j.aeolia.2011.02.001.

Sharma, S., 1996: Applied MultivariateTechniques. John Wiley, 512 pp.

Smirnov, A., and Coauthors, 2002: Atmospheric aerosol optical properties in the Persian Gulf. J. Atmos. Sci., 59, 620-634, doi:10.1175/1520-0469(2002)059<0620:AAOPIT > 2.0.CO;2.

Sugar, C. A., and G. M. James, 2003: Finding the number of clusters in a dataset: An information-theoretic approach. J. Amer. Stat. Assoc., 98, 750-763, doi:10.1198/016214503000000666.

Tanaka, T. Y., and M. Chiba, 2006: A numerical study of the contributions of dust source regions to the global dust budget. Global Planet. Change, 52, 88-104, doi:10.1016/ j.gloplacha.2006.02.002.

Tindale, N. W., and P. P. Pease, 1999: Aerosols over the Arabian Sea: Atmospheric transport pathways and concentrations of dust and sea salt. Deep-Sea Res. II, 46,1577-1595, doi:10.1016/ S0967-0645(99)00036-3.

Tyrlis, E., J. Lelieveld, and B. Steil, 2013: The summer circulation over the eastern Mediterranean and the Middle East: Influence of the South Asian monsoon. Climate Dyn., 40, 11031123, doi:10.1007/s00382-012-1528-4.

Washington, R., M. Todd, N. J. Middleton, and A. S. Goudie, 2003: Dust-storm source areas determined by the Total Ozone Monitoring Spectrometer and surface observations. Ann. Assoc. Amer. Geogr., 93, 297-313, doi:10.1111/1467-8306.9302003.

Wilkerson, W. D., 1991: Dust and sand forecasting in Iraq and adjoining countries. Rep. AWS/TN-91/001, Air Weather Service, Scott AFB, IL, 63 pp.

Zender, C. S., H. Bian, and D. Newman, 2003: Mineral Dust Entrainment and Deposition (DEAD) model: Description and 1990s dust climatology. J. Geophys. Res., 108, 4416, doi:10.1029/ 2002JD002775.

Zhu, A., V. Ramanathan, F. Li, and D. Kim, 2007: Dust plumes over the Pacific, Indian, and Atlantic Oceans: Climatology and radiative impact. J. Geophys. Res., 112, D16208, doi:10.1029/ 2007JD008427. 